\title{
Research Support for Danish Physics
}

\section{O. W. Dietrich, F. Øster and A. R. Mackintosh, Copenhagen}

Danish scientists have played an important part in the development of physics since the time of Tycho Brahe, whose accurate astronomical observations were a vital factor in the scientific revolution of the sixteenth and seventeenth centuries. Ole Rømer's deduction of the finite velocity of light, H.C. Ørsted's discovery of electromagnetism, and a host of lesser but significant discoveries by Danish physicists contributed to the description of the Universe in terms of the great intellectual construction of classical physics. As is well known, Niels Bohr played a central role in the modern scientific revolution, and created an Institute for Theoretical Physics in Copenhagen which is considered as one of the world's great scientific institutions.

At the end of the nineteen-fifties, Danish physics research was dominated by the Niels Bohr Institute. Since then, however, a series of new institutions have been created; for example, the H.C. Ørsted Institute of the University of Copenhagen, the Risø National Laboratory, the new campus of the Technical University in Lyngby, the Physics Institute of Aarhus University, and the new universities in Odense, Roskilde and Aalborg. Some of the resulting expansion in physics research has occurred within nuclear and elementary particle physics, the principal research areas of the Bohr Institute, but most of it has been due to the development, from essentially nothing, of flourishing new research fields, especially within atomic and condensed matter physics.

The pattern of Danish physics has thus changed dramatically in the past two decades, and in 1977 the Board of the Danish Physical Society appointed a Committee, under the Chairmanship of O.W. Dietrich, to "survey the development of physics research in Denmark since the late nineteen-fifties, describe the situation as it is today, and indicate possible future trends". The Committee was particularly requested to collect suitable statistical material, which it did by means of questionnaires which were sent to the physics laboratories in the country. A report based on this material was issued at the beginning of 1979 , to- gether with a description of research in solid state physics in Denmark, which is intended as the first of a series covering the major sub-fields of physics. These reports, which are in Danish, can be obtained from the Danish Physical Society. In this article, we present a survey of the investments in physics research in Denmark during the past two decades and of results obtained. It covers the following subfields of physics in Denmark : nuclear, elementary particle, condensed matter, atomic, molecular, and plasma physics.

\section{Results of Study}

As shown in Fig. 1, the manpower devoted to physics research, which must be considered as the most important component of a successful research programme, more than tripled in the nineteen-sixties, but has shown a slight fall in the seventies. This fall is more than accounted for by the decrease in the number of research stipends (salaries which cover both pre- and post-doctoral research), also illustrated in Fig. 1, which is a very disturbing trend. The amount of technical assistance available to the individual scientist has roughly doubled over the past twenty years, as increasingly complex equipment has been developed.

The total investment in physics research, shown in Fig. 2, grew by more than a factor of five between 1957 and 1973 (in fixed prices), but has remained roughly constant since. The most significant single item is salaries, which have increased spec-

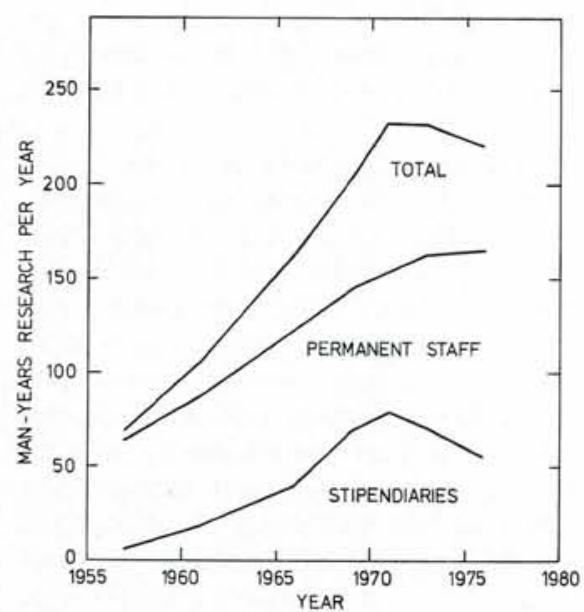

tacularly, both because of increased manpower and increased individual salaries. The running expenses for the individual research projects grew rapidly in the early nineteen-sixties, but have since declined slightly. Periodic investments have been made in both buildings and major equipment, the largest of which were the DR3 reactor at Risø, the Tandem Accelerator at the Niels Bohr Institute, and the Physics Institute at Aarhus University. The support given to international activities, particularly CERN and ESA, has increased steadily.

It is more difficult to measure over the past two decades the output of Danish physics, in the form of new discoveries. The Bohr Institute was already recognized as one of the world's leading centres in nuclear and elementary particle physics at the beginning of this period, and there is no indication that the quality of the research in Denmark in these areas has declined since then. The situation in the sub-fields which started essentially from scratch at the end of the nineteen-fifties has been rather different. There are strong indications that the quality of the published work has improved as the physicists in these areas have matured and developed their technical skill.

There is little doubt that increasing numbers of Danish physicists have become internationally recognized in the past two decades, but such recognition is, by its nature, difficult to quantify. Since the end product of a successful research project is a publication in which the results are presented, we have adopted the number of such publications as a rough

Fig. 1 - The number of man-years devoted to physics research in Denmark per year, and the contributions of permanent staff and stipendiaries, for the year 1957-76.

Fig. 3 - The total number of papers published in refereed journals by Danish physicists per year, and the number per man-year of research, for the years 1957-76.

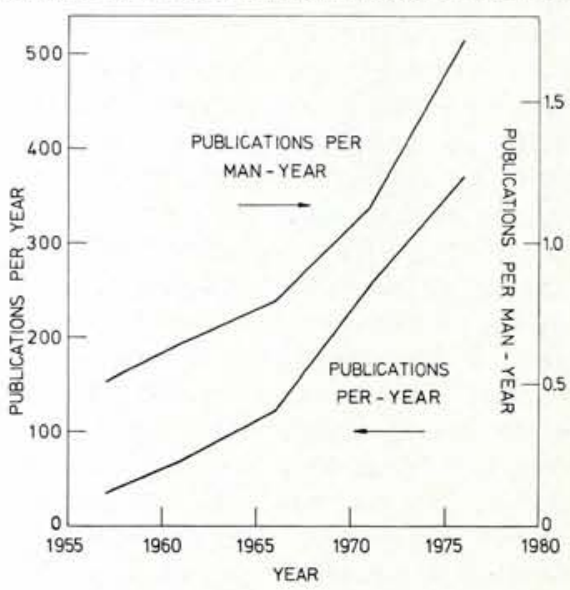


measure of research output. We have satisfied ourselves that the average length of published articles has not declined during the period of the study (rather the contrary), but have not attempted to evaluate their quality, except by including only publications in refereed international journals.

As shown in Fig. 3, the increased investment in physics in the past twenty years has been accompanied by an order - of - magnitude increase in the annual number of publications. The productivity of the individual scientist, measured in these terms, has more than tripled. Despite the uncertainties inherent in our relatively crude method of measuring research output, this figure gives unequivocal evidence of the increase in productivity of the Danish physics community over the past two decades.

The study has revealed therefore that Denmark made a continuously increasing investment in physics research from the late nineteen-fifties to about 1970, and this investment was reflected in a spectacular increase in the results obtained. In the nineteenseventies, the annual financial investment remained roughly constant, although there was a slight decrease in manpower, whereas the productivity, measured in terms of the number of articles published, has continued to increase. This pattern may perhaps be typical for a number of European countries. The statistical evidence on which these conclusions are based suffers in many cases from substantial uncertainty, but the general trends are clear.

It is apparent that the expansion of physics research in Denmark has, at least temporarily, come to a halt. The failure to obtain political approval for a heavy ion accelerator for the Niels Bohr Institute, on economic grounds, even though the scientific merit of the project was generally accepted, was a recent manifestation of this situation. Most Danish physics laboratories are at present well equipped, and there are a few large installations in the country which are internationally competitive. However, it is clear that research which requires large and expensive facilities will increasingly be performed through international collaboration, so that the increasing trend in the contributions to multinational laboratories is likely to continue. It is possible, of course, that such a laboratory could be placed in Denmark, where the scientific and technical skills undoubtedly exist to make such a venture a success.

The greatest threat to the future of Danish physics lies in the declining

Fig. 2 - The annual investment in physics research in Denmark for the years 1957-76, corrected to fixed prices in 1976 kroner. The curves have been smoothed to eliminate fluctuations due, for example, ot the establishment of large facilities. "Overhead" refers to the common expenses of universities or research establishments. 4 kroner in 1976 prices are roughly equivalent to 1 Sw.Fr. today.

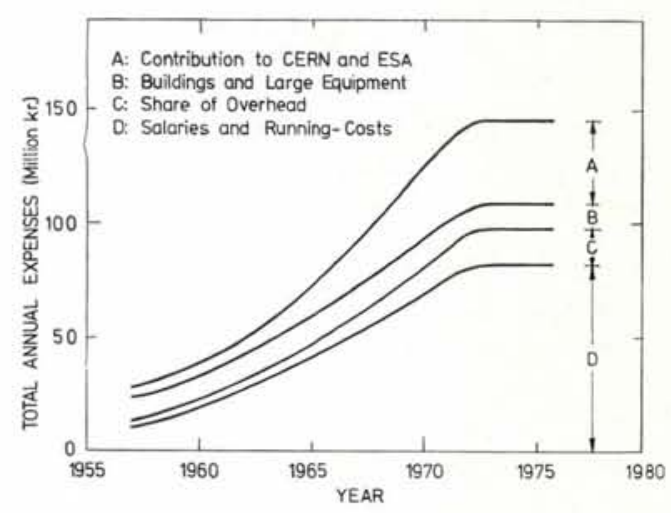

recruitment of young scientists. The decrease in numbers of those who obtain stipends to embark upon a career in physics research, and the consequent increasing average age of Danish physicists, will begin to have serious consequences in the near future, unless steps are taken to reverse this trend. The authorities are aware of this problem, which is felt throughout the scientific community in Denmark, and the Planning Council for Research recently produced a report in which various novel proposals for countering it were made, taking into account the present difficult economic situation.

\section{European Journal of Physics}

Contributions in the form of articles, or letters and comments, for publication in the new journal of the European Physical Society published by The Institute of Physics - European Journal of Physics - are invited by the Editor, G.W. Series. They should be sent to the Managing Editor of the journal at The Institute of Physics, Publishing Division, Techno House, Redcliffe Way, Bristol BS1 6NX, England. Two copies should be submitted with an additional copy of the title page and abstract in English. Style should follow the Europhysics Style Manual. Subscription enquiries should be sent to the Circulation Manager at the address given above.

The new journal has been created to promote the exchange of ideas on physics as it is taught in Universities and other institutes of higher education. Its function is to communicate to its readers the ideas of those whose business it is to teach, and it will provide a forum for the discussion of new, and possibly controversial, ideas on well established topics in physics.

The journal will publish contributions in the following categories : articles which are explicitly education- al, that is, of a tutorial or pedagogical nature on particular topics in physics, or relating to methods of teaching physics as practised in particular institutions or countries, or relating to the University training of school teachers ; articles of a reflective nature that bear on the fundamentals of physics or that offer new insights into known phenomena in physics ;

articles crossing the boundaries between physics and other scientific disciplines ;

articles on the cultural implications of physics.

\section{Belgian Contribution}

Following the contribution of the Novo Foundation in Denmark of 30000 DKr (see EN, May 1979, p. 7) the Belgian Physical Society, after celebrating in November the 50th Anniversary of its foundation, has announced that the Belgian Ministry of National Education and French Culture has made a grant of $100000 \mathrm{BF}$ to the European Physical Society to help support the initial launch expenses of the European Journal of Physics. These expenses have been estimated to be as much as 20000 